\title{
Cardio-respiratory changes among farmers and non-farmers in Rafi Local Government Area, Niger State, Nigeria.
}

\author{
${ }^{1}$ Tanko, Y., ${ }^{1}$ Eze, E. D. ${ }^{1}$ Jimoh, A., ${ }^{1}$ Yusuf, M., ${ }^{1}$ Mohammed, K. A., ${ }^{3}$ Balarabe,F., \\ ${ }^{2}$ M. G. Magaji, ${ }^{1}$ Mohammed, A. \\ ${ }^{I}$ Department of Human Physiology, Faculty of Medicine, Ahmadu Bello University, \\ Zaria, Nigeria. \\ ${ }^{2}$ Department of Nursing Sciences, Faculty of Medicine, Ahmadu Bello University, Zaria, Nigeria
}

\begin{abstract}
The study investigated cardio-respiratory functions in farmers and non-farmers in Rafi Local Government Area of Niger State. The parameters assessed were the blood pressure, pulse rate, peak expiratory flow rate, mean arterial blood pressure and body mass index. Two hundred apparently healthy subjects of ages between 15-50 years were divided into two groups of hundred subjects each. Group I served as the control (Non-farmers) and Group II were used as the experimental group. The results showed no significant change $(P>0.05)$ in the systolic, diastolic, pulse rate and mean arterial blood pressure in the farmers when compared with the non-farmers. However, the peak flow rate decreased significantly $(P<0.05)$ in the farmers when compared with the non-farmers. Also, as regards to the body mass index, there was a significant decrease $(P<0.05)$ in the farmers when compared with the non-farmers. In conclusion, there was a decrease in the peak flow rate and basal metabolic rate in farmers.
\end{abstract}

Key words: Blood pressure, famer, body mass index, systolic, diastolic, peak flow rate

\section{Introduction}

The cardiovascular system includes the heart and all of the blood vessels that carry blood to and from the organs. It transports oxygen and nutrients to cells and carbon dioxide and metabolic wastes away from cells. Blood vessels include arteries, veins, and capillaries, which are all connected and work in unison with the lungs to deliver oxygen to the brain, heart, and other vital organs. The respiratory system includes the passages from the nose and sinuses down into the smallest airways of the lungs (Vander et al., 2001). The respiratory system consist of the upper airway which includes - nose, oral cavity, pharynx and larynx and the lower airway consisting of the trachea-bronchial tree and a series of bronchial airways (Jardins, 2000; Louie, 2001). Farmers and farm workers are conditioned to the physical activities and to the environment of farm work. The present work was aimed at assessing the cardiorespiratory changes among farmers and non-farmers in Rafi Local Government Area, Niger State, Nigeria.

\section{Materials And Methods}

\subsection{Location and duration of the study}

This research work was done out at Rafi Local Government Area, Niger State, Nigeria in the Month of September, 2010.

\subsection{Material Used}

These include: Meter rule, Weighing scale, cotton wool, Wright peak flow meter, digital vitalograph (Model S-48917), Vitalograph paper, Mouth piece of vitalograph, dettol, water and digital blood pressure monitor (Omron MX2 (HEM-742-E2) S/N 20081205060LF)

\subsection{Data collection technique}

A total of 200 subjects were used for this work, with 100 subjects serving as control group and the other 100 subjects consisting of the test group. All the 200 subjects were Nigerians and random sampling technique was employed in selecting the subjects with their ages ranged between 15-50 years which constitutes the active farming ages in the area. This was facilitated by the use of questionnaire.

\subsection{Vitalograph experiment}

The subjects were made to inspire maximally and then expire into the mouth piece that was inserted on the pipe of the vitalograph machine. The breadth was held until the vitalograph pencil reached the end of the vitalograph paper. FVC and $\mathrm{FEV}_{1}$ were calculated from the result on the vitalogaph paper. 


\subsection{Determination of blood pressure}

Briefly, the arm cuff of the digital blood pressure monitor was carefully wapped around the subject left arm just above the cubital fossa. The cuff was inflated by the machine to a certain pressure and the systolic, diastolic and pulse rate was taken respectively.

\subsection{Determination of peak expiratory flow rate (PEFR)}

A Wright peak flow meter was used. Briefly, the mouth of this apparatus was constantly disinfected with dettol before each use by the subject. The subject took maximal inspiration and then gives out a maximal expiration and the PEFR was read directly from the meter scale. A reset was made to return the pointer to zero and manoeuvre was repeated. The best of the three broadly reproducible attempts was taken as the PEFR

\subsection{Determination of height}

The height of subjects was measured by the use of a meter rule. The subjects stood without shoes and caps against a wall that is calibrated in meters and their heights were taken.

\subsubsection{Determination of weight}

This was determined using a bathroom weighing scale. The subjects stood on the scale without phones or anything that could alter their appropriate weight and their weight was taken.

\subsection{Body Mass index (BMI)}

The weight of the subjects was taken using bath room scale without shoe. The subject standing erect looking straight ahead without shoes while the height was measured using a meter rule.

\subsection{Statistical analysis}

Random sampling technique was used in this study. Data obtained were expressed as mean \pm SEM for both the control and the experimental group and statistical comparison of measured variables between the two groups were carried out using independent students' t- test and the difference among means calculated at a level of $\mathrm{p}<0.05$ indicating significance (Duncan et al.,1977).

\section{Results}

Table 1: Mean ( \pm SEM) values of cardio-respiratory parameters of control and experimental groups.

\begin{tabular}{lll}
\hline Parametres & Control group & Experimental group \\
\hline Systolic blood pressure $(\mathrm{mmHg})$ & $125.82 \pm 1.67$ & $127 \pm 1.77^{\mathrm{ns}}$ \\
Diastolic blood pressure $(\mathrm{mmHg})$ & $76.89 \pm 1.55$ & $74.85 \pm 1.18^{\mathrm{ns}}$ \\
$\begin{array}{l}\text { Mean arterial blood pressure } \\
\text { (mmHg) }\end{array}$ & $93.22 \pm 1.46$ & $92.36 \pm 1.23^{\mathrm{ns}}$ \\
Pulse rate (beat $/ \mathrm{min})$ & $77.27 \pm 1.44$ & $76.27 \pm 1.44^{\mathrm{ns}}$ \\
Peak flow rate $(\mathrm{L} / \mathrm{min})$ & $318.73 \pm 7.36$ & $356.47 \pm 7.28^{\mathrm{a}}$ \\
Body mass index $\left(\mathrm{kg} / \mathrm{m}^{2}\right)$ & $24.76 \pm 0.39$ & $21.71 \pm 0.34^{\mathrm{a}}$ \\
\hline
\end{tabular}

${ }^{\mathrm{a}} \mathrm{P}<0.05$ are statistically significant when compared to control group while $\mathrm{ns}=$ not significant

TABLE 1 shows the mean values of cardio-respiratory parameters of control and experimental groups. Results obtained in this study showed that there was no statistically significant difference ( $p>0.05)$ in all cardiovascular parameters in the experimental groups when compared to the control group. However, there was significantly increased $(\mathrm{p}<0.05)$ peak flow rate in the experimental group when compared to the control group. The body mass index decreased significantly $(\mathrm{p}<0.05)$ in the experimental group when compared to the control group.

\section{Discussion}

The present study assessed the cardiorespiratory changes among farmers and non-farmers in Rafi Local Government Area, Niger State, Nigeria. Results showed a non-significant increase in systolic blood pressure farmers when compared to the control group. There was also no statistically significant $(p>0.05)$ change in diastolic change in diastolic blood pressure in farmers when compared to non-farmers in the area studied. In the same vein, the mean arterial blood pressure and pulse rate was significantly decreased $(p>0.05)$ in the farmers when compared to the control group respectively. However, the peak flow rate showed a significant increased $(\mathrm{p}<0.05)$ in the farmers when compared to the control group. Result of the body mass index obtained revealed a statistically significantly increased $(p<0.05)$ in the farmers when compared to the non-farmers 


\section{Conclusion}

In conclusion, the results obtained in this study revealed that there was a significant change in peak flow rate and body mass index, with no significant changes observed in systolic blood pressure, diastolic blood pressure, mean arterial blood pressure and pulse rate in farmers assessed when compared to non-farmers.

\section{References}

[1] A. Vander, J. Sherman and D. Luciano, Circulation In: Human Physiology; The mechanism of body function, $8^{\text {th }}$ ed. (McGrawHill. 14, 2001) 442-444.

[2] T.D. Jardins, (2002). Exercise and its effect on cardiopulmonary system In: Cadiopulmonary anatomy and physiology, $4^{\text {th }}$ ed. (Delmar. 17, 2002) 443-454.

[3] D. Louie, "The effects of cigarette smoking on cardiopulmonary function and exercise tolerance in teenagers," Canadian Respiratory: Journal of the Canadian Thoracic Society 8(4), 2001, 289-91.

[4] R.C. Duncan, R.G. Knapp and M.C. Miller, Test of hypothesis in population means. In: Introductory Biostatistics for the health sciences. (John Wiley and Sons Inc. NY, 1977) pp. 71-96. 